\section{NREL's Renewable Energy Development}

\section{Expertise Reduces Project Risks}

\section{Helps Execute a Major Solar Deal in the U.S. Virgin Islands}

A successful renewable energy project requires a deep understanding of the various risks faced by the utility and the project developers. NREL's deployment team leverages decades of technical expertise and experience implementing utility-scale renewable energy projects to help all parties understand and avoid project development pitfalls.

In the U.S. Virgin Islands (USVI), NREL helped the Virgin Islands Energy Office and the Virgin Islands Water and Power Authority (WAPA) realistically assess the territory's clean energy resources and identify the most viable and cost-effective solutions to its energy challenges - resulting in a \$65 million investment in solar in the USVI

\section{Committing to Cut Fossil Fuel Use 60\% by 2025}

Faced with electricity prices more than four times higher than the U.S. average, USVI Gov. John P. de Jongh Jr. set an aggressive goal in 2010 to reduce the territory's dependence on fossil fuel $60 \%$ by 2025 . He was committed to developing the USVI's renewable energy resources and increasing its energy security. But there were a variety of hurdles to overcome - not the least of which were a faltering economy, insufficient expertise in renewable energy, and a need for unbiased and experienced guidance in clean energy technology deployment.

In February 2010, the governor signed a memorandum of understanding with the U.S. Department of Energy and the U.S. Department of the Interior launching the Energy Development in Island Nations initiative's USVI pilot project (EDIN-USVI). As a project partner, the USVI was able to tap into NREL's unbiased energy expertise and benefit from a broad spectrum of technical assistance and project development support.

NREL worked with a diverse set of public and private stakeholders to identify the territory's baseline energy use and help determine how the USVI could best meet its $60 \%$ goal by deploying a combination of wind, solar, waste-to-energy, landfill gas, and energy efficiency technologies. This baseline energy assessment pointed to solar resource development as an important first step on the road to meeting the USVI's aggressive clean energy goal.

\section{Attracting Quality Developers}

Drawing upon NREL's deep technical expertise and project development experience, WAPA was able to reduce the risks associated with renewable energy development, attract quality developers, and ensure that proposed solar projects could be financed successfully. NREL support included:

- Helping identify optimal sites for solar photovoltaic (PV) systems

- Identifying policy and regulatory changes that would address current barriers, such as uncertainty around interconnection procedures and agreements (continued on back)
Energy Development in Island Nations Promotes Island Energy Security

Regardless of their geographical location, most islands share two things in common: heavy dependence on costly imported oil and an abundance of domestic renewable energy resources.

The international partnership for Energy Development in Island Nations (EDIN) aims to help island nations and territories around the world increase their energy security by adopting energy efficiency measures and deploying renewable energy technologies.

Formed in 2008, the EDIN partnership includes Iceland, New Zealand, and the United States. To achieve the partners goal of advancing island clean energy deployment, EDIN provides information, training, and technical assistance to support strategic energy planning and project implementation.

As island nations and territories look to clean energy technologies for sustainable solutions to their energy challenges, they stand to benefit from the groundbreaking experience of early adopters. By compiling and sharing experiential data from clean energy deployment projects such as those in the USVI, EDIN assists islands around the world in charting a course toward a sustainable energy future.

For more information about EDIN and the work it is doing to promote island energy security, visit edinenergy.org.
"This is not only a significant event for the territory but for solar energy everywhere." —WAPA Executive Director Hugo Hodge Jr. 


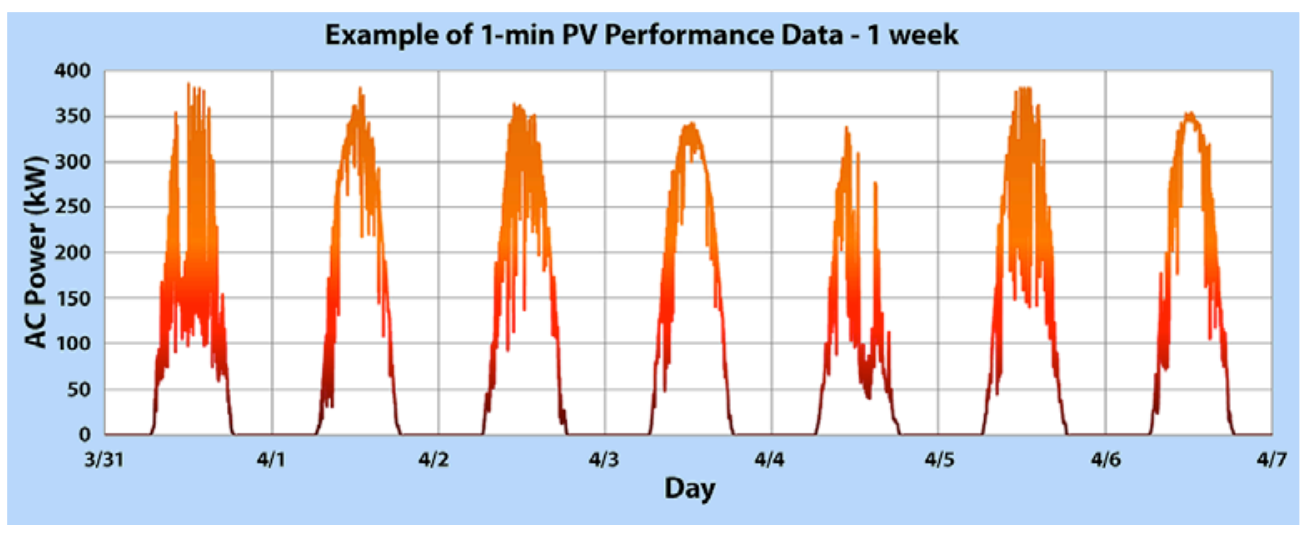

This example of performance data collected from the Cyril E. King Airport PV system on St. Thomas demonstrates the minute-to-minute variability of solar power due to variations in cloud cover.

- Updating the USVI's solar resource assessment to more accurately gauge the potential impact of solar energy in the territory

- Modeling the WAPA grid and developing a strategy to avoid grid integration issues by distributing PV systems geographically

- Analyzing financial and resource dataincluding 1-minute data from a 451-kilowatthour ( $\mathrm{kWh}$ ) solar PV system installed at the airport on St. Thomas-to model the effects of high-penetration renewable energy on the existing WAPA generation system and grid.

Thanks to NREL's technical assistance, including its review of the 27 proposals WAPA received in response to its request for proposals for solar project development, the utility signed six power purchase agreements (PPAs) on June 4, 2012 —one with Toshiba International Corporation, one with Lanco Solar, and four with SunEdison-for a combined 18 megawatts (MW) of solar energy.

\section{Raising the Bar for Renewable Energy Penetration}

By the end of 2013, the three companies will invest a combined total of $\$ 65$ million to install six roof- and ground-mounted PV arrays: three on St. Croix and three on St. Thomas. The PV systems will generate $9 \mathrm{MW}$ of solar power in each district, which WAPA will purchase at an average cost of approximately $\$ 0.18 / \mathrm{kWh}$ over the 25 -year term of the projects. Not only is this significantly lower than what it would cost the utility to produce the same amount of diesel-generated power at its plants, but it represents a groundbreaking shift in the territory's energy economy — and sets a new standard for community renewable penetration.
On St. Croix specifically, 9 MW of solar power represents nearly $20 \%$ of the island's peak demand, an unprecedented level of renewable energy penetration for a community of its size.

"I don't know of another area or jurisdiction anywhere that has that significant of a portion of their peak demand in a renewable resource such as solar, so this is not only a significant event for the territory but for solar energy everywhere," said WAPA Executive Director Hugo Hodge Jr.

\section{Charting the Course for Island Clean Energy}

Like many island communities, the USVI is almost $100 \%$ dependent on imported oil for electricity and transportation, leaving it vulnerable to global oil price fluctuations that can have devastating economic effects. But through its leadership on the clean energy front, the USVI is charting the course to a more secure energy future for the Caribbean region and for islands around the world.

The USVI's successful renewable projects provide a model for other islands to follow in developing their renewable resources, showcase the technical and economic viability of high-penetration renewable energy on islands, and guide other island communities in fundamentally changing the way they generate and use energy.

For more information on NREL's efforts to advance island clean energy goals, visit: www.nrel.gov/tech_deployment/tech_ assistance_islands.html
NREL's deployment and market

transformation activities

encompass the laboratory's full

range of technologies, which

span the energy efficiency and

renewable energy spectrum.

NREL staff educates partners on

how they can advance sustainable

energy applications and also

provides clients with best practices

for reducing barriers to innovation

and market transformation.

NREL's mission is to be the leader

in technology innovation and to

advance renewable energy efforts

around the world. Let NREL help

propel your organization toward a

more sustainable energy future.
National Renewable Energy Laboratory

15013 Denver West Parkway

Golden, C0 80401

303-275-3000 • www.nrel.gov

NREL is a national laboratory of the

U.S. Department of Energy,

Office of Energy Efficiency and Renewable

Energy, operated by the Alliance for

Sustainable Energy, LLC.

NREL/FS-7A20-56183・ December 2012
Front page photography (from the top): Don Buchanan/ VIEO 19338; Kelly Gloger/Solar Delivered 20815; Don Buchanan/VIEO 20152 and 20124; Adam Warren, NRELI PIX 18953 